\title{
Preserved Enzymatic Activity of Glucose Oxidase Immobilized on Unmodified Electrodes for Glucose Detection
}

Gang Wang

City university of New York

Ngee Mei Thai

Follow this and additional works at: https://engagedscholarship.csuohio.edu/enece_facpub

ci-Tung Yau Cleveland State University, s.yau@csuohio.edu

How does access to this work benefit you? Let us know!

Publisher's Statement

NOTICE: this is the author's version of a work that was accepted for publication in Biosensors \& Bioelectronics. Changes resulting from the publishing process, such as peer review, editing, corrections, structural formatting, and other quality control mechanisms may not be reflected in this document. Changes may have been made to this work since it was submitted for publication. A definitive version was subsequently published in Biosensors \& Bioelectronics, 22, 9-10, (04-15-2007); 10.1016/j.bios.2006.10.015

\section{Original Citation}

Wang, G., Thai, N. M., , \& Yau, S. (2007). Preserved enzymatic activity of glucose oxidase immobilized on unmodified electrodes for glucose detection. Biosensors and Bioelectronics, 22(9-10), 2158-2164.

doi:10.1016/j.bios.2006.10.015

\section{Repository Citation}

Wang, Gang; Thai, Ngee Mei; and Yau, Siu-Tung, "Preserved Enzymatic Activity of Glucose Oxidase Immobilized on Unmodified Electrodes for Glucose Detection" (2007). Electrical Engineering \& Computer Science Faculty Publications. 56.

https://engagedscholarship.csuohio.edu/enece_facpub/56

This Article is brought to you for free and open access by the Electrical Engineering \& Computer Science Department at EngagedScholarship@CSU. It has been accepted for inclusion in Electrical Engineering \& Computer Science Faculty Publications by an authorized administrator of EngagedScholarship@CSU. For more information, please contact library.es@csuohio.edu. 


\title{
Preserved enzymatic activity of glucose oxidase immobilized on unmodified electrodes for glucose detection
}

\author{
Gang Wang ${ }^{1}$, Ngee Mei Thai, Siu-Tung Yau ${ }^{*, 1}$ \\ Department of Physics and Astronomy, Hunter College of City University of New York, New York, NY 10021, United States
}

\section{Introduction}

Electron transfer at the protein-electrode interface has been a subject of extensive research in bioelectronics devices (Armstrong and Wilson, 2000; Heller, 1990; Katz et al., 2004; Xiao et al., 2003). Bioelectronic devices such as biosensors (Battaglini et al., 2000; Gooding et al., 1998; Yu et al., 2003) and bio-fuel cells (Chen et al., 2001; Mano et al., 2002, 2003; Willner, 2002) basically perform two functions, namely, molecular recognition and enzyme-electrode communication (Benson et al., 2001). A device with superior performance is characterized by fast enzyme-electrode electron transfer (communication) with the enzyme being able to perform molecular recognition. The most obvious approach to achieving enhanced electron transfer is to immobilize enzymes directly onto the bare/unmodified electrode surface (Bonanni et al., 2003;
Heering et al., 2004; Wang et al., 2006; Wang and Yau, 2005). However, inorganic electrodes and enzymes are incompatible materials that, in general, enzymes undergo denaturation upon immobilization on bare electrodes (Wen et al., 1997) and, therefore, lose their enzymatic activities. The general approach to solving this problem is to modify the electrode surface with a layer of organic material or carbon nanotubes to protect the enzymes against denaturation (Benson et al., 2001; Cai and Chen, 2004; Gooding et al., 2003; Guiseppi-Elie et al., 2002; Luong et al., 2004; Zhao et al., 2002a,b). However, the interfacial layer adds impedance to electron transfer. Thus, the problem of achieving fast interfacial electron transfer while preserving enzymatic activity becomes that of finding a biocompatible electrode so that the enzyme can be immobilized on the unmodified electrode surface.

Glucose oxidase (GOx) is an ideal model enzyme for bioelectrochemistry (Wilson and Turner, 1992). Modified electrodes are believed to be indispensable for the electrochemistry of immobilized GOx. Generally, GOx was immobilized on electrodes that were modified with different materials such as self-assembled monolayer (SAM) (Gooding et al., 1998; Jiang et al., 1995; Rubin et al., 1996; Zhang et al., 2004), films of organic materials 
(Arrigant and Bartlett, 1998), nanoparticles (Liu and Ju, 2003; Liu et al., 2003) and nanotubes (Cai and Chen, 2004; GuiseppiElie et al., 2002; Lin et al., 2004; Luong et al., 2004; Zhao et al., 2002a), the electron transfer rate constant of $0.026-1.7 \mathrm{~s}^{-1}$ were reported. GOx also has been immobilized on unmodified electrodes and its enzymatic activity was not observed due to denaturation (Wen et al., 1997). In particular, immobilization of GOx on unmodified electrode has been attempted using the basal plane of HOPG (bpHOPG) (Chi et al., 1994a,b). No redox characteristics were observed with GOx adsorbed on bpHOPG. Although well-defined redox peaks were observed when anodized bpHOPG was used to immobilize GOx (Chi et al., 1994a,b; Zhang et al., 1995), the electrode showed no enzymatic activity when glucose was introduced to the electrode environment.

HOPG and other graphite-related materials play an important role and have been used as electrode materials in many applications. There are some reviews (Banks and Compton, 2005a; Banks and Compton, 2006) on the applications of epHOPG. bpHOPG can be used for detection of azide (Xu and Swain, 1999), and epHOPG can be used to detect ascorbic acid (Wantz et al., 2005), halide (Lowe et al., 2005), NADH (Banks and Compton, 2005b) and glucose (Wang et al., 2006).

The feasibility of using silicon in bioelectronics has been explored due to the maturity of silicon microelectronic technology. The etched silicon surface, which is hydrophobic, gives rise to severe protein denaturation (Lu et al., 1998). The mostly used method for modifying the silicon surface involves covalent attachment of organics such as thiol and peptides to the native and synthesized oxide on silicon (Rusin et al., 1992; Volle et al., 2003). However, the resultant siloxane is hydrolytically unstable under physiological conditions, and it is difficult to achieve efficient electron transfer between the electrode and immobilized enzymes. Silicon dioxide has been shown to cause no denaturation to immobilized proteins due to its hydrophilic nature $\mathrm{Su}$ et al., 1998; Wang and Yau, 2005).

In this article, we report the observation of the redox reaction and enzymatic activity of GOx immobilized on unmodified surface of epHOPG and $\mathrm{SiO}_{2} / \mathrm{Si}$. Facile electron transfer between the immobilized GOx and the electrode is obtained using cyclic voltammetry, and the voltammograms show a formal potential that is in agreement with the formal potential of the native GOx. The enzymatic activity of the immobilized GOx is demonstrated by exposing the electrode to glucose following conditions that illustrate the catalytic effect of GOx.

\section{Materials and methods}

\subsection{Chemicals and apparatus}

GOx (EC 1.1.3.4, 15.5 U/mg, from Aspergillus niger) and $\beta-\mathrm{D}(+)$-glucose are purchased from Sigma and use as received. The ZYH grade HOPG is purchased from GE Advanced Ceramics. All other chemicals are of analytical grade and use without further purification. All solutions are prepared with water $(18.2 \mathrm{M} \Omega \mathrm{cm})$ from a Direct- $\mathrm{Q}^{\mathrm{TM}} 5$ Millipore system. Glucose solutions are left overnight before use to allow equilibration of anomers. PBS with various $\mathrm{pH}$ values is prepared by mixing stock standard solutions of $\mathrm{Na}_{2} \mathrm{HPO}_{4}$ and $\mathrm{KH}_{2} \mathrm{PO}_{4}$ and adjusting the $\mathrm{pH}$ with $0.1 \mathrm{M} \mathrm{H}_{3} \mathrm{PO}_{4}$ or $\mathrm{NaOH}$.

The electrochemical measurement system consisted of a conventional three-electrode cell and a potentiostat (Princeton Applied Research, Model 283). GOx modified electrodes are used as the working electrode. A commercial $\mathrm{Ag} / \mathrm{AgCl}$ (3 M $\mathrm{KCl}$, Microelectrode Inc.) electrode is used as the reference electrode. A platinum wire is used as the counter electrode. All potentials are measured and reported versus the $\mathrm{Ag} / \mathrm{AgCl}$ electrode and all experiments are carried out at room temperature $\left(22 \pm 1{ }^{\circ} \mathrm{C}\right)$. Cyclic voltammetry experiments are performed in deoxygenated PBS, which is obtained by bubbling the PBS with highly pure nitrogen for $15 \mathrm{~min}$ and maintains under nitrogen atmosphere during measurements. Oxygen-saturated PBS is used in the experiments for glucose determination and electrocatalytical studies.

\subsection{Modification of the electrodes}

A fresh bpHOPG is obtained by cleaving the basal plane with common adhesive tape. The epHOPG is prepared according the literature (Banks and Compton, 2005a; Wang et al., 2006) by fracturing a $10 \mathrm{~mm} \times 10 \mathrm{~mm} \times 0.5 \mathrm{~mm}$ HOPG piece, the fresh epHOPG surface is then rinsed with water before experiments. GOx is dissolved in $10.0 \mathrm{mM}$ phosphate buffer solution (PBS) at $\mathrm{pH} 3.8$ and the concentration is $10.0 \mathrm{mg} / \mathrm{mL}$. A drop of GOx solution is placed on the entire epHOPG electrode for $1 \mathrm{~h}$ with the electrode sealed inside a container with moisture. GOx is physically adsorbed on the bpHOPG and epHOPG electrodes. After adsorption, the electrode is rinsed with the buffer solution and transfer immediately to the electrochemical cell.

Heavily doped $(\rho<0.005 \Omega \mathrm{cm})$ n-type silicon wafers with (1 11 1) orientation are used to immobilize GOx. The wafer with its surface containing the native oxide $\left(\mathrm{SiO}_{2}\right)$ is soaked in a solution $\left(30 \% \mathrm{H}_{2} \mathrm{O}_{2}: 98 \% \mathrm{NH}_{3} \mathrm{H}_{2} \mathrm{O}: \mathrm{H}_{2} \mathrm{O}=1: 1: 5\right.$, v/v) for $30 \mathrm{~min}$ as we reported before (Wang and Yau, 2005). The solution not only removes contaminants on the $\mathrm{SiO}_{2}$ surface, but also improves the number of silanol groups on the surface, thus making the surface more hydrophilic. After rinsing in ethanol, isopropanol and deionized water, the surface is covered with a mask to achieve a working area of $1 \mathrm{~mm} \times 1 \mathrm{~mm}$. A drop of $10.0 \mathrm{mg} / \mathrm{ml} \mathrm{GOx}$ in PBS ( $\mathrm{pH} 3.8,10.0 \mathrm{mM}$ ) is placed on the $\mathrm{SiO}_{2}$ surface and the sample is incubated for $4 \mathrm{~h}$ as above. The $\mathrm{GOx} / \mathrm{SiO}_{2} / \mathrm{Si}$ electrode is finally rinsed with buffer solution. Silicon wafers that are etched using $49 \% \mathrm{HF}$ are also used to immobilize GOx to form the $\mathrm{GOx} / \mathrm{Si}$ electrode.

\section{Results and discussion}

\subsection{Electrochemistry of GOx/epHOPG and GOx/bpHOPG}

The cyclic voltammograms (CVs) of different electrodes in $\mathrm{pH}$ 7.0 PBS are recorded at $50 \mathrm{mV} \mathrm{s}^{-1}$. No redox peaks are observed at bare bpHOPG, epHOPG and GOx/bpHOPG electrode with surface area of $1 \mathrm{~mm}^{2}$ in $\mathrm{pH} 7.0 \mathrm{PBS}$ at the potential 


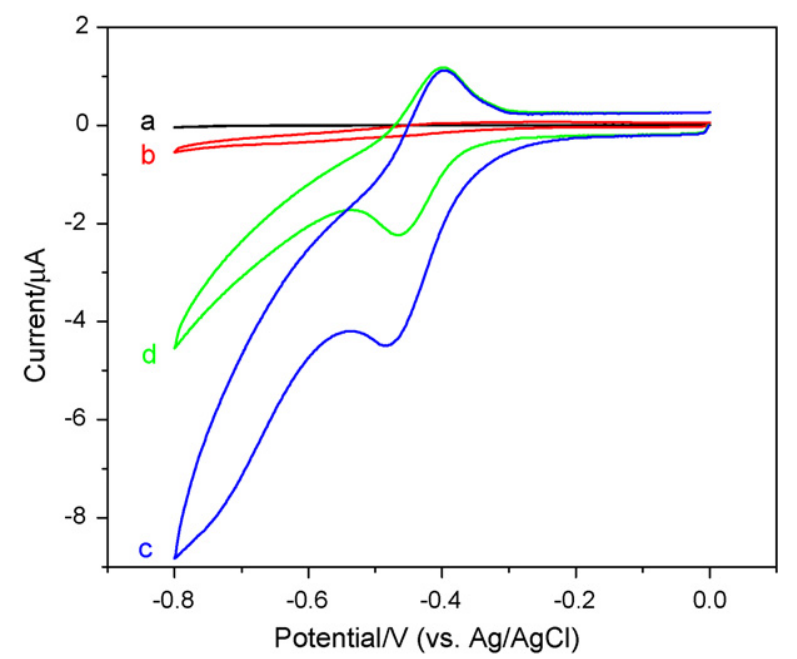

Fig. 1. Cyclic voltammograms of three kinds of bpHOPG electrodes: (a) $0.01 \mathrm{~cm}^{2}$ bare bpHOPG electrode; (b) $0.01 \mathrm{~cm}^{2} \mathrm{GOx} / \mathrm{bpHOPG}$ electrode that was used to obtain curve a; (c) first cycle; (d) fourth cycle of CVs of $\mathrm{GOx} / \mathrm{bpHOPG}$ electrode with surface area $0.28 \mathrm{~cm}^{2}$. The voltammograms were obtained in a $10.0 \mathrm{mM}$ pH $7 \mathrm{PBS}$ at $50 \mathrm{mV} / \mathrm{s}$.

range of $-0.8-0.0 \mathrm{~V}$. Fig. 1 shows the CVs of three kinds of bpHOPG electrode. No peaks are present on $1 \mathrm{~mm}^{2}$ bare bpHOPG electrode. When GOx is immobilized on the same electrode, the voltammogram, curve $b$, still shows no redox peaks. But when GOx is adsorbed on a $28.3 \mathrm{~mm}^{2} \mathrm{bpHOPG}$ electrode, the voltammogram, curves $\mathrm{c}$ and $\mathrm{d}$, show a pair of redox peaks with the formal potential located at $-0.435 \mathrm{~V}$ (reduction peak at $-0.47 \mathrm{~V}$ and oxidation peak at $-0.40 \mathrm{~V}$ ). The bpHOPG itself is electrochemically inert and ideally should contain no carbon-oxygen functional groups such as the carboxylic and phenolic groups. However, the small amount of functional groups that in reality does exist on the bpHOPG is caused by damage due to manufacturing or cleaving processes. Therefore, as shown in Fig. 1, a small GOx/bpHOPG electrode shows no redox peaks (curve b) while a considerably larger electrode of the same kind shows the peaks (curves c and d) due to a larger amount of defect (damage)-related functional groups. These peaks are attributed to the redox of the electroactive center of GOx. But the CVs of GOx/bpHOPG change with the scanning, curve $\mathrm{c}$ is the first scan of GOx/bpHOPG and curve $\mathrm{d}$ is the $\mathrm{CV}$ recorded after several scans, as shown in Fig. 1, the reduction peak changes with the increasing of scanning, while there is no such change for the oxidation peak.

The results of Fig. 1 imply that the redox reaction of immobilized GOx has a preference to the functional groups on the surface of electrode. It is known that the epHOPG contains a large number of carbon-oxygen functional groups (Armstrong et al., 1989; Kamau et al., 1985). These groups are created by rupturing the carbon-carbon bonds of the aromatic rings of the basal plane. When the ruptured bonds are oxidized, carbon-oxygen functional groups such as the carboxylic and phenolic groups are formed (Armstrong et al., 1989; Kamau et al., 1985). These groups render hydrophilicity and ionic character to the edge plane, thus providing immobilization interaction. And these groups can promote the electron transfer and bridge electron transfer pathway between the enzyme and electrode (Ghindilis et al., 1997; Xu et al., 2004).

After adding $10.0 \mathrm{mg} / \mathrm{ml}$ GOx into PBS, a pair of redox waves was obtained on epHOPG electrode. The cathodic and anodic peak potentials are -0.45 and $-0.39 \mathrm{~V}$, respectively. The formal potential of GOx is $-0.42 \mathrm{~V}$. When the GOx/epHOPG electrode is exposed to pH7.0 PBS, a couple of stable and well-defined peaks are observed. Obviously, these peaks are attributed to the redox of the electroactive center of GOx. The peak potentials are located at -0.46 and $-0.39 \mathrm{~V}$ with a formal potential of $-0.425 \mathrm{~V}$. The redox curves are very stable even after several scan cycles. And the redox potentials are almost same at the different scan rates. Fig. 2 shows CVs of GOx/epHOPG electrode at different scan rates. With scan rate increasing from 10 to $200 \mathrm{mV} \mathrm{s}^{-1}$, the peak current shows linear response to the scan rate (Fig. 2 inset), indicating a surface controlled process (Laviron, 1979; Zhao et al., 2002a). The interfacial electron transfer of GOx/epHOPG electrode is estimated using the method of Laviron (1979). Since the peak-peak separation of the voltammogram is less than $200 \mathrm{mV}$, the kinetics of the electron transfer is analyzed using a transfer coefficient $\alpha$ of 0.5 , and the electron transfer rate constant $k_{\text {et }}$ is estimated to be $2 \mathrm{~s}^{-1}$. This value of $k_{\text {et }}$ is much larger than $1 \times 10^{-5} \mathrm{~s}^{-1}$ obtained on lipid bilayer films modified graphite electrode (Tominaga et al., 1997) and $0.026 \mathrm{~s}^{-1}$ obtained using a gold electrode that was modified with 3,3'-dithiobis-sulfocinnimidylpropionate (DTSSP) (Jiang et al., 1995). Also, this $k_{\text {et }}$ value is larger than the value of $1.5-1.7 \mathrm{~s}^{-1}$ obtained using an electrode that was modified with carbon nanotubes (Cai and Chen, 2004; Guiseppi-Elie et al., 2002; Zhao et al., 2002a) suggesting this is a faster electron transfer process. We attribute this enhanced electron transfer to that fact that the GOx is making direct contact to the unmodified electrode. Integrating both the cathodic and the anodic peaks of the $\mathrm{CV}$ at a scan rate of $100 \mathrm{mV} / \mathrm{s}$ yields a surface coverage of $3.07 \times 10^{-12} \mathrm{~mol} / \mathrm{cm}^{2}$.

The redox reaction of the native GOx is due to that of the $\mathrm{FAD} / \mathrm{FADH}_{2}$ redox couple (Ianniello et al., 1982), which

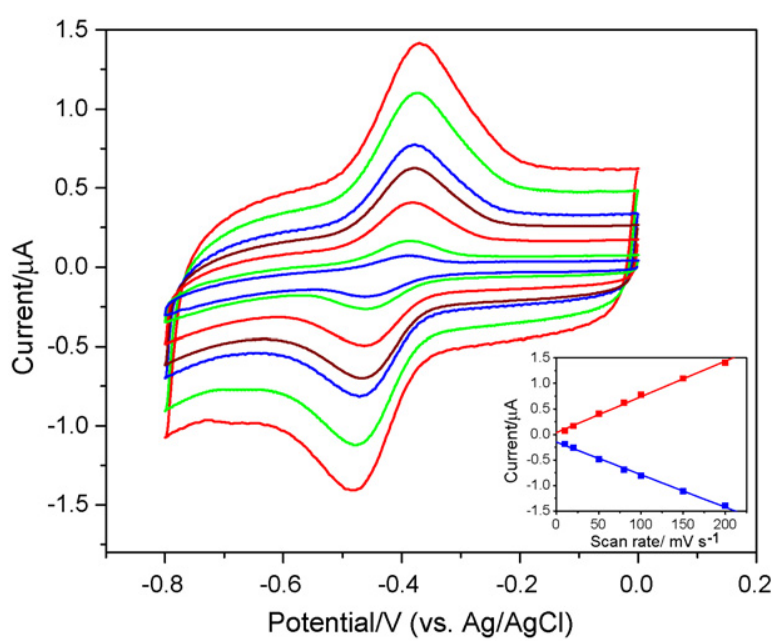

Fig. 2. Effect of scan rate on the CVs of GOx/epHOPG electrode in $10.0 \mathrm{mM} \mathrm{pH}$ 7.0 PBS (from inner to outer curves: 10, 20, 50, 80, 100, 150 and $200 \mathrm{mV} \mathrm{s}^{-1}$ ); (inset) plot of peak current vs. scan rate from 10 to $200 \mathrm{mV} \mathrm{s}^{-1}$. 


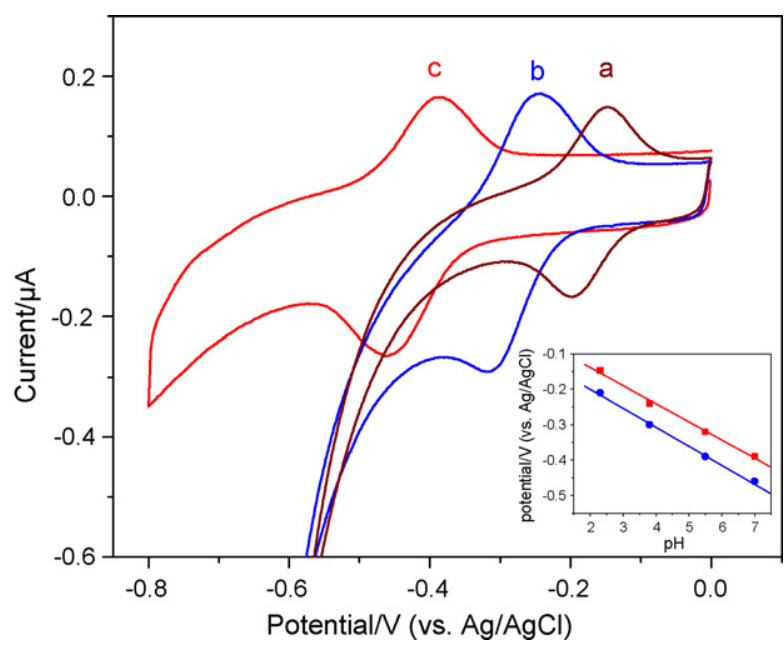

Fig. 3. Cyclic voltammograms of a GOx/epHOPG electrode obtained at $100 \mathrm{mV} / \mathrm{s}$ in a $10.0 \mathrm{mM}$ PBS at pH 2.3 (curve a), 3.8 (curve b) and 7.0 (curve c). The inset shows plots of peak potentials vs. $\mathrm{pH}$.

involves the transfer of two protons and two electrons (Savitri and Mitra, 1998; Scheller et al., 1979). The formal potential of the $\mathrm{FAD} / \mathrm{FADH}_{2}$ redox couple at $\mathrm{pH} 7.0$ is $-0.43 \mathrm{~V}$ versus $\mathrm{Ag} / \mathrm{AgCl}$ (Tinoco et al., 1978). Curve of Fig. 2 shows that the measured formal potential of GOx adsorbed on the epHOPG electrode is $-0.425 \mathrm{~V}$, which is in good agreement with value of the native molecule. Therefore, it is very likely that GOx retains its native conformation and hence its enzymatic activity when immobilized on the epHOPG.

The features of the cyclic voltammogram of the GOx/ epHOPG electrode show a strong dependence on the $\mathrm{pH}$ of the electrolytic solution as shown in Fig. 3. As solution pH decreasing causes a positive shift in both oxidation and reduction peak potentials, where curves $\mathrm{a}, \mathrm{b}$ and $\mathrm{c}$ are the cyclic voltammograms in 10.0 mM PBS at pH 2.3,3.8 and 7.0, respectively. All changes in peak potentials and peak currents with $\mathrm{pH}$ are reversible in the $\mathrm{pH}$ range of 2.3-7.0. That is, the same voltammogram can be obtained if the electrode is transferred from a solution with a different $\mathrm{pH}$ value back to its original solution. The inset of Fig. 3 is a plot of the peak potential versus $\mathrm{pH}$ (from 2.3 to 7.0), featuring two straight lines. The upper line, referring to the oxidation peak potential, has a slope of $-51.7 \mathrm{mV} / \mathrm{pH}$ (linear regression coefficient $=0.9998$ ), while the lower line, referring to the reduction peak potential, has a slope of $-53.5 \mathrm{mV} / \mathrm{pH}$ (linear regression coefficient $=0.9959)$. These values are close to the expected value of $-58.5 \mathrm{mV} / \mathrm{pH}$ (Liu and Ju, 2003). Therefore, these values confirm that two protons $\left(2 \mathrm{H}^{+}\right)$and two electrons $\left(2 \mathrm{e}^{-}\right)$participate in the electron transfer process of the redox reaction of GOx. These results also show that GOx immobilized on the epHOPG can reserve their nature activity at acidic solution even lower to $\mathrm{pH} 2.3$.

\subsection{Electrochemistry of $\mathrm{GOx} / \mathrm{SiO}_{2} / \mathrm{Si}$}

The results of cyclic voltammetry of $\mathrm{GOx} / \mathrm{SiO}_{2} / \mathrm{Si}$, as shown in Fig. 4, show no redox processes occurring with the GOx/Si electrode in the potential range where the redox peaks of GOx

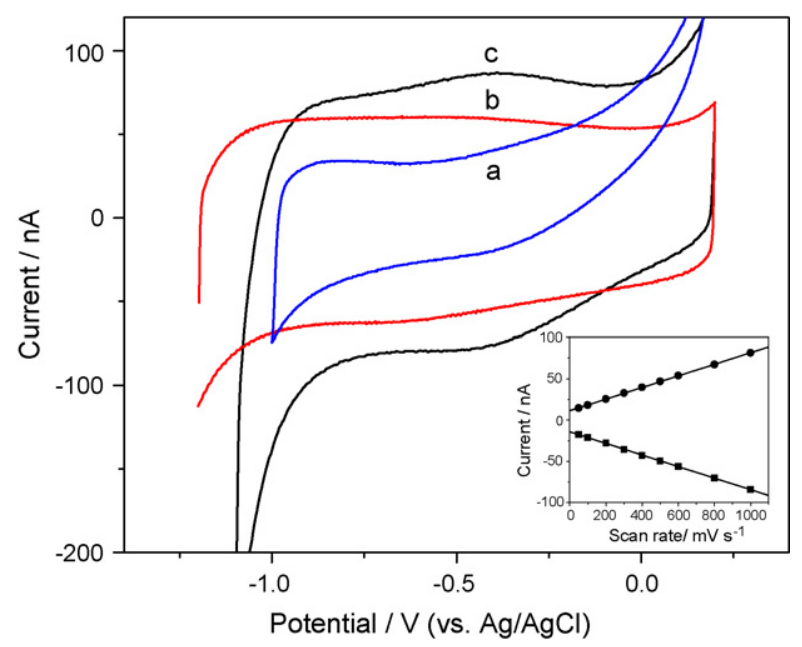

Fig. 4. Cyclic voltammograms of the (a) $\mathrm{SiO}_{2} / \mathrm{Si}$ electrode, (b) $\mathrm{GOx} / \mathrm{Si}$ electrode and (c) $\mathrm{GOx} / \mathrm{SiO}_{2} / \mathrm{Si}$ electrode in $10.0 \mathrm{mM}$ deoxygenated $\mathrm{PBS}(\mathrm{pH} 7.0)$ at a scan rate of $100 \mathrm{mV} / \mathrm{s}$ (vs. $\mathrm{Ag} / \mathrm{AgCl}$.); (inset) plots of oxidation peak current and reduction peak current vs. potential scan rate, $v$, of the same $\mathrm{GOx} / \mathrm{SiO}_{2} / \mathrm{Si}$ electrode.

are expected to appear (Cai and Chen, 2004; Guiseppi-Elie et al., 2002; Zhao et al., 2002a) and $\mathrm{SiO}_{2} / \mathrm{Si}$ electrode. However, the $\mathrm{CV}$ of the $\mathrm{GOx} / \mathrm{SiO}_{2} / \mathrm{Si}$ electrode shows two peaks located at -0.44 and $-0.42 \mathrm{~V}$, also in agreement with previous results (Cai and Chen, 2004; Guiseppi-Elie et al., 2002; Jiang et al., 1995; Tominaga et al., 1997; Zhao et al., 2002a). The scan rate dependence of the peak currents of the $\mathrm{GOx} / \mathrm{SiO}_{2} / \mathrm{Si}$ electrode is plotted in Fig. 4 inset. The linear dependence of the peak currents on the scan rate indicates that the redox reaction observed is due to GOx immobilized on the electrode. Therefore, the measured formal potential of $-0.43 \mathrm{~V}$ versus $\mathrm{Ag} / \mathrm{AgCl}$ is in good agreement with value of the native molecule. Therefore, it is also very likely that GOx retains its native conformation and hence its enzymatic activity when immobilized on the native oxide. The electron transfer rate constant $k_{\mathrm{et}}$ at $\mathrm{GOx}-\mathrm{SiO}_{2}$ interface is estimated to be $7.9 \mathrm{~s}^{-1}$ by using the method of Laviron.

\subsection{Enzymatic activity of GOx/epHOPG}

As shown above, the measured formal potential of GOx immobilized on the epHOPG is in good agreement with that of the native molecule. However, the ultimate test that the immobilized enzyme retains its enzymatic activity is to carry out the actual catalysis of its substrate. The GOx induced electrocatalysis of glucose can be carried out by increasing the potential in the positive polarity to about $0.7 \mathrm{~V}$ in the absence of oxygen (Xiao et al., 2003). Oxidation of glucose results in transporting electrons from glucose via GOx to the epHOPG electrode. Fig. 5A shows the response of the GOx/epHOPG electrode to glucose. However, we chose to use the negative potential range ( -0.8 to $0.0 \mathrm{~V}$ as we use above) to avoid interference such as ascorbic acid and uric acid due to high positive potentials (Liu and Ju, 2003; Zhang et al., 2004). Also, the working in the negative potential range allows one to observe simultaneously the enzyme-electrode electron transfer during catalysis. In our experiment, the GOx/epHOPG electrode is used as the working 


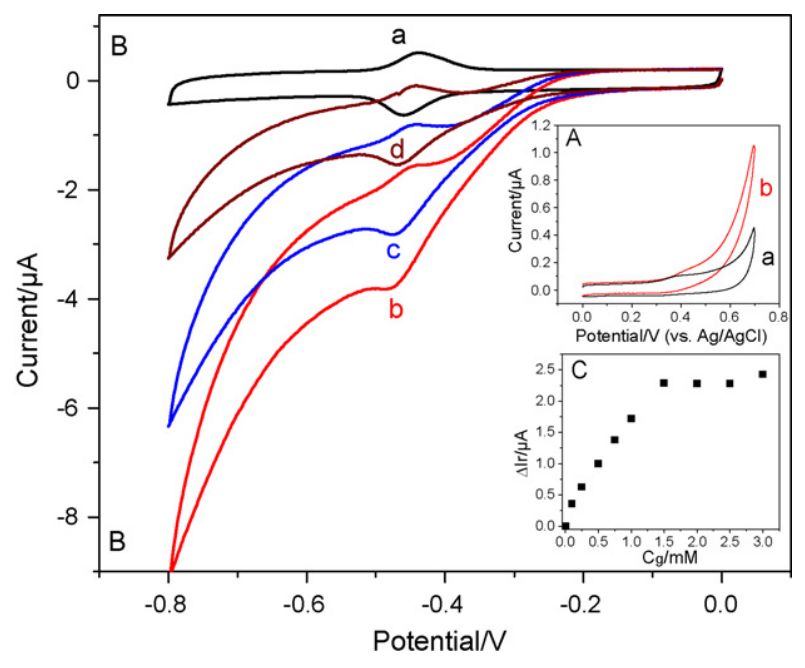

Fig. 5. (A) CVs to the bioelectrocatalyzed oxidation of glucose by GOx/epHOPG electrode in the presence of $10.0 \mathrm{mM} \mathrm{pH} 7.0 \mathrm{PBS}$ with (a) $0 \mathrm{mM}$ glucose and (b) $10.0 \mathrm{mM}$ glucose under $\mathrm{N}_{2}$. (B) CVs of the GOx/epHOPG electrode in (a) deoxygenated $10.0 \mathrm{mM} \mathrm{pH} 7.0 \mathrm{PBS}$, (b) oxygen-saturated $10.0 \mathrm{mM}$ pH 7.0 PBS, (c) $0.5 \mathrm{mM}$ glucose and (d) $1.5 \mathrm{mM}$ glucose in $10.0 \mathrm{mM}$ oxygensaturated $\mathrm{pH}$ 7.0 PBS at $50 \mathrm{mV} \mathrm{s}^{-1}$. (C) Plot of electrocatalytic reduction current $\Delta I_{\mathrm{r}}$ vs. $C_{\mathrm{g}}$.

electrode in cyclic voltammetry measurements, subjected to the following conditions:

$\mathrm{GOx}(\mathrm{FAD})+2 \mathrm{e}^{-}+2 \mathrm{H}^{+} \rightleftharpoons \mathrm{GOx}\left(\mathrm{FADH}_{2}\right)$

(Reaction 1) in deoxygenated PBS

$$
\mathrm{Gox}\left(\mathrm{FADH}_{2}\right)+\mathrm{O}_{2} \rightarrow \mathrm{GOx}(\mathrm{FAD})+\mathrm{H}_{2} \mathrm{O}_{2}
$$

(Reaction2) in oxygen-saturated PBS

glucose $+\mathrm{O}_{2} \stackrel{\text { GOx }}{\longrightarrow}$ gluconolactone $+\mathrm{H}_{2} \mathrm{O}_{2}$

(Reaction 3) in oxygen-saturated PBS

The three reactions are a protocol for detecting glucose by monitoring the change in the reduction current of Reaction 1, which is the redox reaction of the immobilized GOx (Godet et al., 1999; Guiseppi-Elie et al., 2002; Liu and Ju, 2003; Zhang et al., 2004).These conditions correspond to the redox reaction of the immobilized GOx as described by Reaction 1, coupled respectively to the oxidation of $\mathrm{FADH}_{2}$ (Reaction 2) and to the oxidation of glucose (Reaction 3). Fig. 5B shows the voltammograms obtained under the three conditions.

Curve a in Fig. 5B indicates the presence of the redox reaction of GOx immobilized on the epHOPG measured in a deoxygenated PBS (Reaction 1). When the PBS is saturated with oxygen, the voltammogram changed dramatically with an increase of reduction peak current and decreases of oxidation peak current as shown in curve $b$. The increased reduction peak current indicates that the reduced form of GOx in Reaction 1 is oxidized by dissolved oxygen via Reaction 2 so that Reaction 1 favors more reduction of GOx. Upon adding glucose to the oxygensaturated PBS, the reduction peak current decreased as shown in curve c. Being the substrate of GOx, glucose gives rise to a GOx-catalyzed reaction, which also consumes dissolved oxygen as indicated by Reaction 3 . Therefore, because the two competitive reactions (Reactions 2 and 3 ) all consume dissolved oxygen, Reaction 2 and hence the reduction process of Reaction 1 is slowed down. Thus, the reduction peak current decreases with increasing glucose concentration, and the amount of glucose is detected by monitoring the decrease in the reduction peak current of the GOx electrode. Note that no such effect has been observed using electrode immobilized with free FAD or denatured GOx in the literature (Chi et al., 1994a,b; Zhang et al., 1995) and in the present work, which shows that the decrease of the reduction peak current is due to the enzymatic activity of GOx. As shown in Fig. 5B, the magnitude of the reduction peak current decreases with increasing glucose concentration $\left(C_{\mathrm{g}}\right)$ as explained above. Defining $\Delta I_{\mathrm{r}}$ as the difference between the reduction peak current when glucose is present and the reduction peak current without glucose, Fig. $5 \mathrm{C}$ shows that $\Delta I_{\mathrm{r}}$ increases with increasing $C_{\mathrm{g}} . \Delta I_{\mathrm{r}}$ indicates the degree of the catalytic effect of the immobilized GOx on glucose. The calibration curve, which is the $\Delta I_{\mathrm{r}}$ versus $C_{\mathrm{g}}$ plot, of the electrode shows a linear response range from 0.10 to $1.50 \mathrm{mM}$ with a correlation coefficient of 0.997 and a detection limit of $0.050 \mathrm{mM}$ at a signal-to-noise ratio of 3 . From the above, the sensitivity of the $0.04 \mathrm{~cm}^{2} \mathrm{GOx} / \mathrm{epHOPG}$ electrode to glucose was found to be $1.48 \mathrm{~mA} / \mathrm{mM}$. This value is higher than that of $0.76 \mathrm{~mA} / \mathrm{mM}$ at GOx/PEI electrode (Zhang et al., 2004).

\subsection{Enzymatic activity of $\mathrm{GO} x / \mathrm{SiO}_{2} / \mathrm{Si}$}

To demonstrate that the $\mathrm{GOx}-\mathrm{SiO}_{2}$ electrode is indeed a glucose sensor, the faradaic current was measured as the glucose level was varied. The magnitude of the reduction peak current decreases with increasing $C_{\mathrm{g}}$. Defining $\Delta I_{\mathrm{r}}$ as the difference between the reduction peak current when glucose is present and the reduction peak current without glucose, Fig. 6 shows that $\Delta I_{\mathrm{r}}$

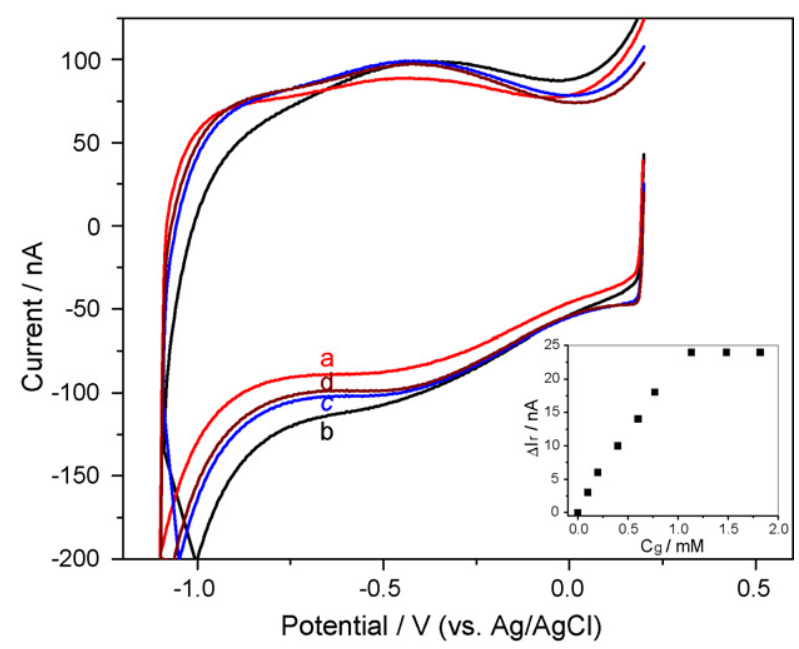

Fig. 6. Cyclic voltammograms of (a) $\mathrm{GOx} / \mathrm{SiO}_{2} / \mathrm{Si}$ electrode in deoxygenated and (b) oxygen-saturated $10.0 \mathrm{mM} \mathrm{PBS}$ at $\mathrm{pH}$ 7. Curve $\mathrm{c}$ and $\mathrm{d}$ show the response of the same electrode to 0.4 and $0.6 \mathrm{mM}$ glucose in $10.0 \mathrm{mM}$ oxygen-saturated PBS at $\mathrm{pH} 7$; (inset) plot of electrocatalytic reduction peak current $\Delta I_{\mathrm{r}}$ vs. glucose concentration $C_{\mathrm{g}}$. 
increases with increasing $C_{\mathrm{g}}$. The range of linear response of the $\Delta I_{\mathrm{r}}$ versus $C_{\mathrm{g}}$ plot of the electrode is from 0.10 to $1.10 \mathrm{mM}$ with a correlation coefficient of 0.99 . The electrode has a glucose detection limit of $0.050 \mathrm{mM}$ at a signal-to-noise ratio of 3 .

\subsection{Stability and reproducibility of the GOx/epHOPG and $\mathrm{GOx} / \mathrm{SiO}_{2} / \mathrm{Si}$ electrode}

When the GOx/epHOPG electrode is stored at $4{ }^{\circ} \mathrm{C}$, it retains $84 \%$ of its initial current response to glucose after intermitted use over a 30-day period. Thus, the epHOPG is very efficient for retaining the enzymatic activity of GOx. The electrode could keep a constant current when successively sweep for 150 cycles when responding to glucose. The electrode performance showed good reproducibility with a relative standard deviations of $6.7 \%$ for the catalytic current determined at the glucose concentration of $1.0 \mathrm{mM}$. This reproducibility is determined based on examining six electrodes. These results indicate that the enzymatic activity of GOx immobilized on the epHOPG is stable, suggesting an alternative scheme for GOx-based amperometric glucose sensing. The $\mathrm{GOx} / \mathrm{SiO}_{2} / \mathrm{Si}$ electrode also retains $75 \%$ of its initial current response to glucose after intermitted use over a 30-day period.

\section{Conclusion}

The redox reaction of GOx immobilized on epHOPG and $\mathrm{SiO}_{2} / \mathrm{Si}$ is observed using cyclic voltammetry. The measured formal potential of the immobilized GOx agrees with that of the native enzyme. The preference of the redox reaction of GOx to the epHOPG electrode as compare to the bpHOPG electrode indicates that the carbon-oxygen functional groups that are abundant in the edge plane play a crucial role in interfacing the enzyme molecule. The functional groups on the electrode surface can promote the electron transfer and bridge electron transfer pathway between the enzyme and electrode. The estimated electron transfer rate of the epHOPG and $\mathrm{SiO}_{2} / \mathrm{Si}$ electrode immobilized GOx is greater than those for which GOx is immobilized on modified electrodes probably due to the fact that the enzyme makes direct contact to the unmodified electrode. The GOx/epHOPG and $\mathrm{GOx} / \mathrm{SiO}_{2} / \mathrm{Si}$ electrodes also show the characteristic response to glucose, an indication that the immobilized GOx has retained its bioactivity. They show a linear range from 0.10 to $1.50 \mathrm{mM}$ for GOx/epHOPG electrode and $0.10-1.10 \mathrm{mM}$ for $\mathrm{GOx} / \mathrm{SiO}_{2} / \mathrm{Si}$ electrode. The experimental results also demonstrate that the immobilized GOx retains bioelectrocatalytic activity for the oxidation of glucose and also the bioelectrocatalytic activity is stable, suggesting the GOx/epHOPG may be used in GOx-based biosensors or as an electrocatalyst for the bioanode in the bio-fuel cells. The method presents here can be easily extended to immobilize and obtain the direct electrochemistry of other enzymes or proteins.

\section{Acknowledgements}

This work is supported by the NIH-SCORE Grant to Hunter College (1S06 GM60654) and a Research Centers in Minority
Institutions award (Grant RR 03037) from the National Center for research Resources of the NIH.

\section{References}

Armstrong, F.A., Wilson, G.S., 2000. Electrochim. Acta 45 (15-16), 2623-2645. Armstrong, F.A., Bond, A.M., Hill, H.A.O., Oliver, B.N., Psalti, I.S.M., 1989. J. Am. Chem. Soc. 111 (26), 9185-9189.

Arrigant, D.W.M., Bartlett, P.N., 1998. Biosens. Bioelectron. 13 (3-4), 293-304.

Banks, C.E., Compton, R.G., 2005a. Anal. Sci. 21 (11), 1263-1268.

Banks, C.E., Compton, R.G., 2005b. Analyst 130 (9), 1232-1239.

Banks, C.E., Compton, R.G., 2006. Analyst 131 (1), 15-21.

Battaglini, F., Bartlett, P.N., Wang, J.H., 2000. Anal. Chem. 72 (3), 502-509.

Benson, D.E., Conrad, D.W., Lorimier, R.M., Trammell, S.C., Hellinga, H.W., 2001. Science 293 (5535), 1641-1644.

Bonanni, B., Alliata, D., Bizzarri, A.R., Cannistraro, S., 2003. ChemPhysChem 4 (11), 1183-1188.

Cai, C.X., Chen, J., 2004. Anal. Biochem. 332 (1), 75-83.

Chen, T., Barton, S.C., Binyamin, G., Gao, Z., Zhang, Y., Kim, H., Heller, A., 2001. J. Am. Chem. Soc. 123 (35), 8630-8631.

Chi, Q.J., Zhang, J.D., Dong, S.J., Wang, E.K., 1994a. Electrochim. Acta 39 (16), 2431-2438.

Chi, Q.J., Zhang, J.D., Dong, S.J., Wang, E.K., 1994b. J. Chem. Soc., Faraday Trans. 90 (14), 2057-2060.

Ghindilis, A.L., Atanasov, P., Wilkins, E., 1997. Electroanalysis 9 (9), 661-674.

Godet, C., Boujtita, M., El Murr, N., 1999. New J. Chem. 23 (8), 795-797.

Gooding, J.J., Praig, V.G., Hall, E.A.H., 1998. Anal. Chem. 70 (11), 2396-2402.

Gooding, J.J., Wibowo, R., Liu, J.Q., Yang, W.R., Losic, D., Orbons, S., Mearns, F.J., Shapter, J.G., Hibbert, D.B., 2003. J. Am. Chem. Soc. 125 (30), 9006-9007.

Guiseppi-Elie, A., Lei, C.H., Baughman, R.H., 2002. Nanotechnology 13 (5), $559-564$

Heering, H.A., Wiertz, F.G.M., Dekker, C., Vries, S.D., 2004. J. Am. Chem. Soc. 126 (35), 11103-11112.

Heller, A., 1990. Account Chem. Res. 23 (5), 128-134.

Ianniello, R.M., Lindsay, T.J., Yacynych, A.M., 1982. Anal. Chem. 54 (7), 1098-1101.

Jiang, L., McNeil, C.J., Cooper, J.M., 1995. Chem. Commun. 12, 1293-1295.

Kamau, G.N., Willis, W.S., Rusling, J.F., 1985. Anal. Chem. 57 (2), 545-551.

Katz, E., Sheeney-Haj-Ichia, L., Willner, I., 2004. Angew. Chem. Int. Ed. 43 (25), 3292-3300.

Laviron, E., 1979. J. Electroanal. Chem. 101 (1), 19-28.

Lin, Y., Taylor, S., Li, H.P., Fernando, K.A.S., Qu, L.W., Wang, W., Gu, L.R., Zhou, B., Sun, Y.P., 2004. J. Mater. Chem. 14 (4), 527-541.

Liu, S.Q., Ju, H.X., 2003. Biosens. Bioelectron. 19 (3), 177-183.

Liu, S.Q., Leech, D., Ju, H.X., 2003. Anal. Lett. 36 (1), 1-19.

Lowe, E.R., Banks, C.E., Compton, R.G., 2005. Electroanalysis 17 (18), $1627-1634$

Lu, J.R., Su, T.J., Thirtle, P.N., Thomas, R.K., Rennie, A.R., Cubitt, R., 1998. J. Colloid Interf. Sci. 206 (1), 212-223.

Luong, J.H.T., Hrapovic, S., Wang, D., Bensebaa, F., Simard, B., 2004. Electroanalysis $16(1-2), 132-139$.

Mano, N., Mao, F., Heller, A., 2002. J. Am. Chem. Soc. 124 (44), 12962-12963.

Mano, N., Mao, F., Heller, A., 2003. J. Am. Chem. Soc. 125 (21), 6588-6594.

Rubin, S., Chow, J.T., Ferraris, J.P., Zawodzinski, T.A.J., 1996. Langmuir 12 (2), 363-370.

Rusin, K.M., Fare, T.L., Stemple, J.Z., 1992. Biosens. Bioelectron. 7 (5), 367-373.

Savitri, D., Mitra, C.K., 1998. Bioelectrochem. Bioenerg. 47 (1), 67-73.

Scheller, F., Strnad, G., Neumann, B., Kuhn, M., Ostrowski, W., 1979. Bioelectrochem. Bioenerg. 6 (2), 117-122.

Su, T.J., Lu, J.R., Thomas, R.K., Cui, Z.F., Penfold, J., 1998. Langmuir 14 (2), $438-455$.

Tinoco, I.J., Sauer, K., Wang, J.C., 1978. Physical Chemistry: Principles and Applications in Biological Sciences. Prentice-Hall, Englewood Cliffs, N.J, p. 624. 
Tominaga, M., Kusano, S., Nakashima, N., 1997. Bioelectrochem. Bioenerg. 42 (1), 59-62.

Volle, J.-N., Chambon, G., Sayah, A., Reymond, C., Fasel, N., Gijs, M.A.M., 2003. Biosens. Bioelectron. 19 (5), 457-464.

Wang, G., Yau, S.-T., 2005. Appl. Phys. Lett. 87 (25), 253901-253903.

Wang, G., Thai, N.M., Yau, S.-T., 2006. Electrochem. Commun. 8 (6), 987-992.

Wantz, F., Banks, C.E., Compton, R.G., 2005. Electroanalysis 17 (17), 1529-1533.

Wen, Z.H., Ye, B.X., Zhou, X.Y., 1997. Electroanalysis 9 (8), 641-644.

Willner, I., 2002. Science 298 (5602), 2407-2408.

Wilson, R., Turner, A.P.F., 1992. Biosens. Bioelectron. 7 (3), 165-185.

Xiao, Y., Patolsky, F., Katz, E., Hainfeld, J.F., Willner, I., 2003. Science 299 (5614), 1877-1881.
Xu, J., Swain, G.M., 1999. Anal. Chem. 71 (20), 4603-4608.

Xu, J.J., Wang, G., Zhang, Q., Zhou, D.M., Chen, H.Y., 2004. Electrochem. Commun. 6 (3), 278-283.

Yu, X., Sotzing, G.A., Papadimitrakopoulos, F., Rusling, J.F., 2003. Anal. Chem. 75 (17), 4565-4571.

Zhang, J.D., Chi, Q.J., Wang, E.K., Dong, S.J., 1995. Electrochim. Acta 40 (6), 733-744.

Zhang, W.J., Huang, Y.X., Dai, H., Wang, X.Y., Fan, C.H., Li, G.X., 2004. Anal. Biochem. 329 (1), 85-90.

Zhao, Y.D., Zhang, W.D., Chen, H., Luo, Q.M., 2002a. Anal. Sci. 18 (8), 939-941.

Zhao, Y.D., Zhang, W.D., Chen, H., Luo, Q.M., Li, S.F.Y., 2002b. Sens. Actuat. B 87 (1), 168-172. 